\title{
Práticas de gestão financeira e sua relação com o desempenho empresarial: um estudo com 200 empresas do centro oeste mineiro
}

\begin{abstract}
André Luis Ribeiro Lima Doutorado em Administração pela Universidade Federal de Lavras - UFLA Professor da Universidade Federal de Viçosa - UFV E-mail: andreluisnep@yahoo.com.br
\end{abstract}

Hudson Carlos Silva Vidal Pontifícia Universidade Católica de Minas Gerais - PUC Minas E-mail: hudsoncarlos.adm@gmail.com

Leonardo Lemos da Silveira Santos Mestrado em Administração pela Universidade Federal de Minas Gerais - UFMG Professor da Universidade Federal de Juiz de Fora - UFJF Rua José Lourenço Kelmer. Martelos. Juiz de Fora/MG. CEP: 36036-330

E-mail: leonardo.lemos@uol.com.br

Ricardo César Alves Doutorado em Administração pela Universidade Federal de Lavras - UFLA Professor da Pontifícia Universidade Católica de Minas Gerais - PUC Minas Avenida Dom José Gaspar, 500. Coração Eucarístico. Belo Horizonte/MG. CEP: 30535901

E-mail: rcesar.alves@uol.com.br

\section{RESUMO}

O presente estudo tem como objetivo avaliar as práticas ligadas à administração financeira e à contabilidade utilizadas pelos gestores de empresas do Centro Oeste de Minas Gerais, buscando entender a relação desse comportamento com o desempenho das organizações. A pesquisa aqui apresentada é classificada como descritiva com abordagem quantitativa. A amostra foi formada por 200 empresas escolhidas por acessibilidade, ou seja, trata-se de uma amostra não probabilística. Os dados foram coletados por meio de uma pesquisa de campo realizada no ano de 2009 , efetuada diretamente com os dirigentes das empresas em seu local de trabalho. O questionário utilizado é composto por questões presentes em outros estudos e por questões elaboradas pelos próprios autores deste estudo. Para tabulação e análise dos dados foi utilizado o software SPSS (Statistical Package For The Social Science). As técnicas utilizadas foram a estatística descritiva e a análise de conglomerados (Cluster), esta última com o objetivo de separar as empresas em dois grupos. As análises de cluster apontam que as empresas podem ser separadas por seu nível de conhecimento e aplicação da gestão financeira. Além disso, o grupo com empresas que apresentam 
Práticas de gestão financeira e sua relação com o desempenho empresarial: um estudo com 200 empresas do centro oeste mineiro

André Luis Ribeiro Lima, Hudson Carlos Silva Vidal, Leonardo Lemos da Silveira Santos, Ricardo César

maior conhecimento e aplicação da gestão financeira foi o grupo que apresentou as melhores médias de desempenho.

Palavras-chave: Gestão financeira. Desempenho empresarial. Micro e pequenas empresas.

\section{Financial management practices and its relationship with organizational performance: a study of 200 companies in the central-western region of Minas Gerais}

\section{ABSTRACT}

The present study aims to assess the practices related to financial management and accounting practices used by managers in the Central-western region of Minas Gerais, seeking to figure out the relationship of this behavior to organizational performance. The research presented here is classified as descriptive with quantitative approach. The sample consisted of 200 companies chosen by accessibility, that is, a non-probabilistic sample. Data were collected by the means of a field survey carried out in 2009, made directly with business leaders in their workplace. The questionnaire applied consists of questions present in other studies and questions prepared by the authors of this study. To tabulation and data analysis the software SPSS (Statistical Package For The Social Sciences) was used. The techniques used were descriptive statistics and cluster analysis, the latter was used in order to separate the companies into two groups. The cluster analyses indicate that companies may be separated by their level of knowledge and application of financial management. Moreover, the group with companies that have greater knowledge and application of financial management was the group with better average performance.

Keywords: Financial Management. Organizational performance. Micro and small enterprises.

\section{INTRODUÇÃO}

A proposta deste estudo é avaliar as práticas ligadas à administração financeira e à contabilidade utilizada pelos gestores de micro e pequenas empresas no Centro Oeste de Minas Gerais e associá-las ao seu desempenho. "As MPE's possuem algumas características que lhes são próprias, que as tornam essenciais para 0 
Práticas de gestão financeira e sua relação com o desempenho empresarial: um estudo com 200 empresas do centro oeste mineiro

André Luis Ribeiro Lima, Hudson Carlos Silva Vidal, Leonardo Lemos da Silveira Santos, Ricardo César

funcionamento tanto das economias desenvolvidas quanto daquelas em processo de desenvolvimento." (SANTOS; ALVES; ALMEIDA, 2007).

Segundo o Serviço Brasileiro de Apoio às Micros e Pequenas Empresas SEBRAE (2009), as MPE's são responsáveis por cerca de 30\% do Produto Interno Bruto brasileiro e respondem por $60 \%$ dos empregos formais gerados no país. Apesar da importância estratégica como geradora de postos de trabalho, as MPE's enfrentam graves problemas no Brasil, tais como: a globalização da economia, ambientes externos e internos mais dinâmicos e rápidas mudanças nos produtos e processos, em função de avanços tecnológicos. Todos esses fatores contribuem para aumentar o risco e a incerteza, tornando o gerenciamento das empresas uma atividade bastante complexa e desafiante (OTTOBONI; PAMPLONA, 2001).

Apesar disso, segundo pesquisa realizada pelo Serviço Brasileiro de Apoio às Micros e Pequenas Empresas (SEBRAE, 2009), no Brasil, a taxa de mortalidade dessas empresas é de aproximadamente 59,9\% até quatro anos de existência. Outra pesquisa realizada pelo SEBRAE (2009), que tomou por base as empresas registradas na Junta Comercial do Estado de Minas Gerais, mostrou que a "mortalidade" das MPE's mineiras também foi elevada. Os dados coletados apontaram que $45 \%$ das empresas encerraram suas atividades com até dois anos de constituição.

Quanto aos motivos, o resultado foi similar à pesquisa no âmbito nacional. Os entrevistados, representantes das empresas que encerraram suas atividades, apontaram como principais causas do insucesso os seguintes fatores: (a) falta de capital de giro, 45,8\%; (b) carga tributária elevada, 41,7\%; (c) concorrência muito forte, $33,3 \%$; (d) problemas financeiros, $33,3 \%$; e (e) maus pagadores, $20,8 \%$.

Por outro lado, as principais dificuldades enfrentadas pelas empresas que participaram da pesquisa e continuam ativas, foram: (a) carga tributária elevada, $68,2 \%$; (b) falta de capital de giro, 43,6\%; (c) recessão econômica no país, 34,7\%; (d) concorrência muito forte, 33,1\%; e (e) maus pagadores, 22,6\%. Cabello, Galo e Pereira (2007) confirmam a pesquisa do SEBRAE, afirmando que as organizações desse porte 
Práticas de gestão financeira e sua relação com o desempenho empresarial: um estudo com 200 empresas do centro oeste mineiro

André Luis Ribeiro Lima, Hudson Carlos Silva Vidal, Leonardo Lemos da Silveira Santos, Ricardo César

são mais vulneráveis às crises econômicas devido, principalmente, à falta de capital de giro, a alta carga tributária e dificuldade de acesso ao crédito.

Nesse contexto, o presente estudo busca avaliar se empresas que apresentam maior grau de conhecimento e utilização da gestão financeira, são também empresas que apresentam melhor desempenho.

\section{REFERENCIAL TEÓRICO}

\subsection{Micros e Pequenas Empresas}

Segundo Leone (1991) as principais características das pequenas empresas são reflexos de uma gestão informal, da baixa qualificação de mão-de-obra, da escassez de recursos e de técnicas administrativas e, ainda, da falta de capital de giro e de canais de distribuição.

De acordo com Migliato et al. (2004), o conjunto de características gerais quando analisadas em empresas de mesma natureza revela algumas especificidades que, se classificadas, permitem a compreensão de todo o processo gerencial e podem auxiliar na adequação de técnicas e ferramentas utilizadas nas grandes empresas para as de pequeno porte.

Do ponto de vista da gestão financeira dessas empresas, Monteiro (2009) argumenta que estas possuem capacidade e recursos restritos, especialmente quanto ao capital (empréstimos difíceis e fluxo de caixa reduzido).

Matias e Lopes (2002) descrevem que as dificuldades começam no dia-a-dia do proprietário, que por falta de condições para contratação de pessoas eficientes e de confiança para a gestão do negócio, acaba acumulando funções, culminando no inadequado desempenho das atividades gerenciais. Cita ainda que a maior dificuldade das micro e pequenas empresas é o insuficiente preparo gerencial dos dirigentes. As estratégias dessas empresas são estabelecidas confiando muitas vezes em informações e experiências vivenciadas pelos seus administradores, confirmando um fator predominante que influencia diretamente as decisões financeiras de curto prazo. 
Práticas de gestão financeira e sua relação com o desempenho empresarial: um estudo com 200 empresas do centro oeste mineiro André Luis Ribeiro Lima, Hudson Carlos Silva Vidal, Leonardo Lemos da Silveira Santos, Ricardo César

Para Gitman (2010), a gestão financeira é um conjunto de ações e procedimentos administrativos, envolvendo o planejamento, análise e controle das atividades da empresa, visando maximizar os resultados econômicos e financeiros decorrentes de suas atividades operacionais. Cheng e Mendes (1989) afirmam que a administração financeira objetiva encontrar o equilíbrio entre a "rentabilidade" (maximização dos retornos dos proprietários da empresa) e a "liquidez" (que se refere à capacidade de a empresa honrar seus compromissos nos prazos contratados).

A partir das informações levantadas, elaboradas e fornecidas pela contabilidade à administração da empresa por meio de técnicas como: análise e interpretação de balanços, auditoria, contabilidade de custos e controladoria, o gestor pode tomar decisões quanto a investimentos, financiamentos, pagamento das obrigações, momento de substituição de ativos obsoletos (como máquinas, por exemplo), nível ideal de estoque, entre outras (IUDíCIBUS, 2010).

Outro ponto destacado por Leone e Leone (2004) se refere ao crescimento significativo da importância de uma adequada gestão de custos nas organizações, objetivando-se a manutenção e sustentação dessas empresas no mercado competitivo. A sustentabilidade da organização exige dos administradores que se familiarizem com as operações, seus problemas, o fluxo dos recursos que consomem e com os termos técnicos empregados no ambiente organizacional da empresa.

No que concerne à formação dos preços de venda, Martins (2010) afirma que para a sua fixação é necessário conhecer o custo do produto ou serviço, porém, afirma que somente a informação do cálculo do preço de venda a partir do custo não é suficiente devido às mudanças estruturais no mercado, preço praticado pela concorrência e outros fatores. Identificar o custo do produto e escolher a estratégia de precificação é de suma importância para que o preço a ser cobrado proporcione uma margem de lucro almejada.

A administração de caixa também é mencionada por Gitman (2010), ao afirmar que o orçamento de caixa é um demonstrativo das entradas e saídas de caixa planejadas da empresa. É utilizado para estimar as necessidades de caixa em curto 
Práticas de gestão financeira e sua relação com o desempenho empresarial: um estudo com 200 empresas do centro oeste mineiro

André Luis Ribeiro Lima, Hudson Carlos Silva Vidal, Leonardo Lemos da Silveira Santos, Ricardo César

prazo. O orçamento de caixa permite ao gerente financeiro obter uma visão do momento das entradas e saídas de caixa em um dado período.

O equilíbrio financeiro é verificado quando as obrigações financeiras da empresa se encontram lastreadas em ativos com prazos de conversão em caixa similares a dos passivos. O equilíbrio financeiro exige um dado vínculo entre a liquidez dos ativos e os desembolsos demandados pelos passivos (ASSAF NETO; SILVA, 2007).

Quanto à política e concessão de crédito, para a empresa vendedora o prazo de pagamento concedido aos seus clientes representa uma operação financeira denominada crédito comercial. O conjunto das condições sob as quais a empresa efetua suas vendas a prazo constitui a sua política de crédito comercial (SANTOS, 2010). Esta tem por objetivo, além de provocar um incremento no volume de vendas e de buscar equilíbrio entre risco e retorno, promover um ajustamento entre os custos decorrentes do padrão de crédito estabelecido. Após ter fixado a política de crédito, em termos de prazo de pagamento, padrão de cobrança e desconto a ser concedido, a empresa parte para uma segunda etapa: a concessão de crédito ao cliente (SANTOS, 2010).

\subsection{Desempenho Empresarial}

Segundo Silva (2005), embora implicitamente seja usual assumir que as medidas contábeis-financeiras são objetivas e confiáveis, estas podem não ser apropriadas para realização de comparações entre distintas empresas em função das diferenças entre as organizações decorrentes de:

- considerável variabilidade nas práticas contábeis (gerenciais), por exemplo, regimes de depreciação, avaliação de estoques, tratamento de custeio vs. capitalização de diversos itens ( $P \& D$, propaganda, leasing etc.), custos de reposição, métodos de consolidação de demonstrações financeiras, entre outras;

- variabilidade nos regimes fiscais;

- possibilidade de manipulação por parte dos executivos (incluindo, entre outras, práticas de sub ou sobre valorização de ativos ou exigibilidades); 
Práticas de gestão financeira e sua relação com o desempenho empresarial: um estudo com 200 empresas do centro oeste mineiro André Luis Ribeiro Lima, Hudson Carlos Silva Vidal, Leonardo Lemos da Silveira Santos, Ricardo César

Do ponto de vista das limitações das medidas subjetivas e objetivas, Silva (2005) esclarece que a literatura de negócios é farta em razões que explicam as limitações de relatos e retrospectivas de desempenho. Dentre algumas das limitações já documentadas destacam-se as respostas incorretas ou enviesadas em função de motivação pessoal, limitações perceptuais ou cognitivas, informação insuficiente ou solicitação de informação por meio de procedimentos ou instrumentos não apropriados.

Ademais, nem sempre é possível controlar a perspectiva de referência do respondente. Assim, enquanto alguns respondentes podem reportar uma medida percebida absoluta de desempenho, outros podem, mesmo que inadvertidamente, reportar diferenças entre o desempenho percebido e o esperado, ou seja, uma medida relativa. Além disso, o pesquisador não conseguirá controlar o grau de importância que cada respondente atribui a cada aspecto particular do desempenho ou a cada objetivo específico adicionalmente, a própria percepção do que signifique sucesso pode variar entre diferentes respondentes.

Devido a tais limitações é questionável o quanto medidas subjetivas de desempenho serviriam para comparações entre diferentes empresas. Alguns pesquisadores, no entanto, defendem o uso de medidas subjetivas de desempenho uma vez que os gerentes são influenciados por suas próprias percepções ao invés de por dados objetivos "frios" e, além disso, já foi demonstrado que pode se esperar uma alta correlação (convergência) entre medidas subjetivas e medidas objetivas de desempenho.

É com base na perspectiva citada no parágrafo anterior, que o presente estudo utiliza técnicas subjetivas de mensuração do desempenho empresarial. Além disso, segundo Perin e Sampaio (1999), os pesquisadores da área de Administração Estratégica frequentemente encontram dificuldades em obter dados objetivos válidos para a mensuração do desempenho empresarial, bem como em definir quais indicadores melhor representam o desempenho das empresas. Os autores recomendam o uso de indicadores subjetivos (de percepção) como alternativa viável para o caso de inexistência de dados secundários confiáveis. 
Práticas de gestão financeira e sua relação com o desempenho empresarial: um estudo com 200 empresas do centro oeste mineiro

André Luis Ribeiro Lima, Hudson Carlos Silva Vidal, Leonardo Lemos da Silveira Santos, Ricardo César

\section{METODOLOGIA}

\subsection{Universo e Amostra}

Constituem-se como universo da pesquisa as microempresas e pequenas empresas de sete cidades do Centro Oeste de Minas Gerais: Arcos, Lagoa da Prata, Santo Antônio do Monte, Formiga, Bambuí, Pains, Iguatama e Córrego Fundo. Segundo - Instituto Brasileiro de Geografia e Estatística (IBGE, 2007), essas cidades são compostas por um total de 6.823 empresas.

A amostra é formada por 200 empresas sendo: 147 Microempresas (ME), 35 Empresas de Pequeno Porte (EPP) e 18 empresas classificadas como outras (médio porte e grande porte) que atuam nos setores de Comércio, Indústria e Serviço. A amostra é não-probabilística e as empresas escolhidas por acessibilidade. Essa acessibilidade consistiu na permissão e empenho dos entrevistados na pesquisa.

$\mathrm{Na}$ Tabela 1 é apresentado o universo e a amostra da pesquisa, dividida pelo total de empresas examinadas por cidade.

Tabela 1: Universo e amostra da pesquisa

\begin{tabular}{|l|l|l|l|l|l|l|l|l|l|}
\hline Cidade & Arcos & $\begin{array}{l}\text { Lagoa } \\
\text { da } \\
\text { Prata }\end{array}$ & $\begin{array}{l}\text { Santo } \\
\text { Ant. } \\
\text { do }\end{array}$ & Formiga & Bambui & Pains & Iguatama & $\begin{array}{l}\text { Córrego } \\
\text { Fundo }\end{array}$ & Total \\
\hline Universo & 1.465 & 1.179 & 796 & 2.115 & 568 & 268 & 203 & 229 & 6.823 \\
\hline Amostra & 45 & 30 & 29 & 18 & 28 & 19 & 25 & 6 & 200 \\
\hline ME & 32 & 22 & 16 & 13 & 19 & 19 & 22 & 4 & 147 \\
\hline EPP & 11 & 6 & 9 & 3 & 2 & 0 & 2 & 2 & 35 \\
\hline Outra & 2 & 2 & 4 & 2 & 7 & 0 & 1 & 0 & 18 \\
\hline Percentual & $3,07 \%$ & $2,54 \%$ & $3,64 \%$ & $0,85 \%$ & $4,93 \%$ & $7,09 \%$ & $12,32 \%$ & $2,62 \%$ & $2,93 \%$ \\
\hline
\end{tabular}

Fonte: Dados da pesquisa e do IBGE (2007).

\subsection{Coleta e Tratamento dos Dados}

Os dados foram coletados por meio de uma pesquisa de campo realizada diretamente com os dirigentes das empresas em seu local de trabalho. Para a coleta 
Práticas de gestão financeira e sua relação com o desempenho empresarial: um estudo com 200 empresas do centro oeste mineiro

André Luis Ribeiro Lima, Hudson Carlos Silva Vidal, Leonardo Lemos da Silveira Santos, Ricardo César

dos dados foi utilizado um questionário semi-estruturado, composto por 17 questões distribuídas da seguinte maneira: Questões 01 a 08: características das empresas e dos respondentes. Essas questões foram estruturadas com múltipla escolha, tais como: cargo dos respondentes nas empresas, grau de escolaridade, classificação das empresas quanto à legislação tributária, enquadramento tributário e setor de atividade. Já as questões 7 e 8 foram abertas, buscando identificar o tempo de atuação da empresa no mercado e a quantidade de funcionários contratados.

Questões 09 a 15: tipos de controles/anotações feitas nas organizações e utilização das práticas ligadas à administração financeira e contabilidade. Essas questões também foram elaboradas com múltipla escolha apresentando várias alternativas aos respondentes. Na questão 12 fez-se uso da escala tipo likert $(0-8)$ com o objetivo de levantar o grau de utilização e conhecimento teórico dos gestores sobre a administração financeira. As demais questões visaram identificar os tipos de controles/anotações feitos nas empresas (vendas, custos, despesas, investimentos e outros). Foram inseridas questões perguntando se as empresas apuram indicadores financeiros, tais como: geração de lucro, geração de caixa e rentabilidade do patrimônio.

As questões 16 e 17 tiveram como referência estudos citados por Perin e Sampaio (1999), que têm mostrado relações positivas e significativas entre medidas subjetivas de avaliação e desempenho. Nesse caso fez-se uso de questões que tinham como referência de tempo um período de três anos. Na primeira, ao respondente foi solicitado dar uma resposta (de 0 a 10) para o desempenho da empresa em relação às suas expectativas (de muito abaixo do esperado a muito acima do esperado). Na segunda, o desempenho geral da sua empresa com relação aos seus principais concorrentes (de muito pior do que os concorrentes a muito melhor do que os concorrentes). As questões 18 e 19 são referentes ao endividamento das empresas. Por fim, acrescentou-se uma questão dissertativa sobre o que mais afeta, na opinião dos gestores, o desempenho da empresa. 
Práticas de gestão financeira e sua relação com o desempenho empresarial: um estudo com 200 empresas do centro oeste mineiro André Luis Ribeiro Lima, Hudson Carlos Silva Vidal, Leonardo Lemos da Silveira Santos, Ricardo César

O questionário foi então, submetido a um pré-teste em 15 empresas da cidade de Arcos - MG para que ele fosse revisto e aprimorado. Os entrevistadores foram até as empresas cujos gestores (proprietários e/ou gerentes) demonstraram interesse em participar e colaborar com pesquisa em questão. A abordagem aos entrevistados foi realizada na presença do entrevistador, não sendo permitido que os questionários fossem deixados nas empresas e recolhidos em seguida.

\subsection{Análise dos Dados}

Para análise dos dados utilizou-se a estatística multivariada conhecida como análise de clusters (ou agrupamentos). O objetivo foi o de gerar grupos com características homogêneas entre si e diferentes entre os grupos, por meio desta análise. Ressalta-se que para a realização das análises utilizou-se a versão 18.0 do software SPSS (Statistical Package for Social Sciences).

Segundo Malhotra (2006, p.571), "a análise de clusters examina relações de interdependência entre todo o conjunto de variáveis". Neste estudo, realizou-se a análise estatística de cluster a para a formação de dois grupos de empresas com características semelhantes (conhecimento e aplicação da gestão financeira e desempenho).

Fávero (2009) explica que os procedimentos não hierárquicos são métodos que tem como objetivo encontrar diretamente uma partição de " $\mathrm{n}$ " elementos em "K" grupos (clusters), de modo que a participação satisfaça dois requisitos básicos: "coesão" interna e isolamento (ou separação) dos clusters formados. Neste método a partição deve ser definida pelo analista.

Assim, procurou-se separar dois grupos (clusters); um grupo com empresas com maior conhecimento e aplicação da gestão financeira e outro com empresas que apresentaram menor conhecimento e aplicação da gestão financeira. 
Práticas de gestão financeira e sua relação com o desempenho empresarial: um estudo com 200 empresas do centro oeste mineiro André Luis Ribeiro Lima, Hudson Carlos Silva Vidal, Leonardo Lemos da Silveira Santos, Ricardo César Alves

\section{ANÁLISE E DISCUSSÃO DOS RESULTADOS}

\subsection{Variáveis Demográficas, Instrumentos, Ferramentas e Metodologias de Gestão Financeira}

A primeira parte dos questionários apresenta características dos respondentes e das empresas. Identificou-se que $66 \%$ dos entrevistados são proprietários, dentre esses, $12 \%$ possuem ensino fundamental, $25 \%$ possuem ensino médio, $12,5 \%$ possuem curso superior incompleto e 14\% possuem curso superior completo. Nota-se que mais de $3 / 5$ dos entrevistados restringe sua formação educacional ao ensino médio, como mostra a Tabela 2.

Tabela 2: Grau de escolaridade dos respondentes

\begin{tabular}{|c|c|c|c|c|c|c|}
\hline & $\begin{array}{c}\text { Ensino } \\
\text { Fundamental }\end{array}$ & $\begin{array}{c}\text { Ensino } \\
\text { Médio }\end{array}$ & $\begin{array}{c}\text { Superior } \\
\text { incompleto }\end{array}$ & $\begin{array}{c}\text { Superior } \\
\text { completo }\end{array}$ & $\begin{array}{c}\text { Pós- } \\
\text { graduação }\end{array}$ & Total \\
\hline Proprietário & $12 \%$ & $25 \%$ & $12,5 \%$ & $14 \%$ & $2,5 \%$ & $66 \%$ \\
\hline Gerente & $3 \%$ & $15,5 \%$ & $9 \%$ & $5 \%$ & $1,5 \%$ & $34 \%$ \\
\hline Total & $15 \%$ & $40,5 \%$ & $21,5 \%$ & $19 \%$ & $4 \%$ & $100 \%$ \\
\hline
\end{tabular}

Fonte: Dados da pesquisa.

Quanto à classificação das empresas, observa-se na Tabela que 3, que 74,5\% das empresas da amostra são caracterizadas como ME (micro empresas) e 16,5\% são classificadas como EPP (empresa de pequeno porte) e 9\% são classificadas como outras, podendo estas serem empresas de médio ou grande porte, visto que sua definição não foi detalhada nos questionários analisados. 
Práticas de gestão financeira e sua relação com o desempenho empresarial: um estudo com 200 empresas do centro oeste mineiro André Luis Ribeiro Lima, Hudson Carlos Silva Vidal, Leonardo Lemos da Silveira Santos, Ricardo César

Tabela 3: Classificação das empresas

\begin{tabular}{|c|c|c|}
\hline Classificação & Frequência & $\%$ \\
\hline ME & 149 & $74,5 \%$ \\
\hline EPP & 33 & $16,5 \%$ \\
\hline Outra & 18 & $9 \%$ \\
\hline Total & 200 & $100 \%$ \\
\hline
\end{tabular}

Fonte: Dados da pesquisa.

Na Tabela 4 observa-se que 76,5\% das empresas pesquisadas são classificadas como comércio. Os setores de Indústria e Serviço apareceram na amostra com uma participação de $2 \%$ e $8,5 \%$ respectivamente.

Tabela 4: Setor de atividade

\begin{tabular}{|c|c|c|}
\hline Setor de Atividade & Frequência & $\%$ \\
\hline Indústria & 4 & $2 \%$ \\
\hline Comércio & 153 & $76,5 \%$ \\
\hline \hline Serviço & 17 & $8,5 \%$ \\
\hline Indústria e Comércio & 10 & $5 \%$ \\
\hline Indústria e Serviço & 3 & $1,5 \%$ \\
\hline Comércio e serviço & 13 & $6,5 \%$ \\
\hline Total & 200 & $100 \%$ \\
\hline
\end{tabular}

Fonte: Dados da pesquisa

Foi observado que $88,5 \%$ das empresas estão enquadradas no Sistema de Tributação Simples Nacional. O Lucro Presumido apareceu com um percentual de 5\% e o Lucro Real com 6,5\% das empresas analisadas.

Também se observou que a maioria das empresas pesquisadas têm idade superior a 5 anos. As empresas mais jovens, com até 1 ano de existência, representam uma pequena parte da amostra (4\%). O restante das empresas com o tempo de 
Práticas de gestão financeira e sua relação com o desempenho empresarial: um estudo com 200 empresas do centro oeste mineiro

André Luis Ribeiro Lima, Hudson Carlos Silva Vidal, Leonardo Lemos da Silveira Santos, Ricardo César

atuação de 1 a 5 anos representam 17,5\%. O número médio de 11 funcionários foi encontrado por empresa, com um número máximo de 175 funcionários.

$\mathrm{Na}$ Tabela 5 são apresentadas a classificação das empresas e o indicador financeiro lucro. Observa-se que 79\% dos gestores das ME's dizem apurar o resultado (lucro ou prejuízo) de suas empresas em determinado período. Quanto as EPP's, 70\% dos gestores afirmam apurar o resultado de suas empresas. Das empresas denominadas como outras, $89 \%$ apuram o resultado.

Tabela 5: Apuração de resultado

\begin{tabular}{|c|c|c|c|}
\hline Classificação & $\begin{array}{c}\text { Apura o } \\
\text { resultado }\end{array}$ & Não Apura & Total \\
\hline $\mathrm{ME}$ & $79 \%$ & $21 \%$ & $100 \%$ \\
\hline $\mathrm{EPP}$ & $70 \%$ & $30 \%$ & $100 \%$ \\
\hline Outra & $89 \%$ & $11 \%$ & $100 \%$ \\
\hline
\end{tabular}

Fonte: Dados da pesquisa.

$\mathrm{Na}$ Tabela 6 apresenta-se a classificação das empresas questionadas sobre a apuração de caixa. Observa-se que $87 \%$ dos gestores das ME's apuram quanto sobra de caixa em determinado período nas empresas. Nas EPP's, 73\% dos gestores apuram as sobras de caixa periodicamente.

Tabela 6: Apuração de caixa

\begin{tabular}{|c|c|c|c|}
\hline Classificação & $\begin{array}{c}\text { Apura } \\
\text { Caixa }\end{array}$ & $\begin{array}{c}\text { Não } \\
\text { apura }\end{array}$ & Total \\
\hline ME & $87 \%$ & $13 \%$ & $100 \%$ \\
\hline EPP & $73 \%$ & $27 \%$ & $100 \%$ \\
\hline Outra & $94 \%$ & $6 \%$ & $100 \%$ \\
\hline
\end{tabular}

Fonte: Dados da pesquisa

$\mathrm{Na}$ Tabela 7 é apresentada a classificação das empresas questionadas sobre a avaliação do indicador rentabilidade (retorno dividido pelo investimento). Observou-se 
Práticas de gestão financeira e sua relação com o desempenho empresarial: um estudo com 200 empresas do centro oeste mineiro

André Luis Ribeiro Lima, Hudson Carlos Silva Vidal, Leonardo Lemos da Silveira Santos, Ricardo César

que $54 \%$ dos gestores das ME's afirmam apurar rentabilidade de suas empresas. Nas EPP's $55 \%$ dos gestores dizem apurar a rentabilidade.

Tabela 7: Classificação das empresas e o indicador financeiro rentabilidade

\begin{tabular}{|c|c|c|c|}
\hline Classificação & $\begin{array}{c}\text { Empresas } \\
\text { que Apuram } \\
\text { ou Sabe }\end{array}$ & Não apuram & Total \\
\hline ME & $54 \%$ & $46 \%$ & $100 \%$ \\
\hline EPP & $55 \%$ & $45 \%$ & $100 \%$ \\
\hline Outra & $61 \%$ & $39 \%$ & $100 \%$ \\
\hline
\end{tabular}

Fonte: Dados da pesquisa.

Quanto aos tipos de controles/anotações realizados nas empresas, apenas $2 \%$ das ME's não fazem qualquer tipo de controle e/ou anotação, 13\% estimam seus gastos e receitas futuros, $71 \%$ fazem seus controles com base no movimento financeiro realizado, ou seja, no que já aconteceu nas empresas. Por fim, 14\% fazem seus registros e controles com base no estimado e também no realizado. Quanto as EPP's, $3 \%$ não fazem qualquer tipo de controle, $27 \%$ utilizam o controle estimado, $58 \%$ o realizado e $12 \%$ utilizam o controle estimado e realizado. Os dados das empresas denominadas como outras demonstraram que $64 \%$ das empresas fazem seus controles com base no realizado e $36 \%$ com base no realizado e estimado.

Tabela 8: Tipo de controle/anotação

\begin{tabular}{|c|c|c|c|c|c|}
\hline Classificação & Não utiliza & Estimado & Realizado & $\begin{array}{c}\text { Estimado e } \\
\text { Realizado }\end{array}$ & Total \\
\hline ME & $2 \%$ & $13 \%$ & $71 \%$ & $14 \%$ & $100 \%$ \\
\hline EPP & $3 \%$ & $27 \%$ & $58 \%$ & $12 \%$ & $100 \%$ \\
\hline Outra & $0 \%$ & $0 \%$ & $64 \%$ & $36 \%$ & $100 \%$ \\
\hline
\end{tabular}

Fonte: Dados da pesquisa.

Foi examinado como são efetuados os controles/anotações nas empresas. Notase que em $6 \%$ das microempresas não se utiliza qualquer tipo de controle/anotação, 
Práticas de gestão financeira e sua relação com o desempenho empresarial: um estudo com 200 empresas do centro oeste mineiro

André Luis Ribeiro Lima, Hudson Carlos Silva Vidal, Leonardo Lemos da Silveira Santos, Ricardo César

$38 \%$ fazem seus controles em papéis, $16 \%$ fazem seus controles em planilhas, $29 \%$ fazem seus controles em software específico, $5 \%$ utilizam papéis e planilhas, $3 \%$ utilizam planilhas e software e 3\% utilizam papéis e software. Nas EPP's, em 1,5\% não se faz qualquer tipo de controle, $12 \%$ utilizam papéis, $15 \%$ utilizam planilhas, $38 \%$ utilizam software e $21 \%$ utilizam mais de uma ferramenta para fazer seus controles. Já nas empresas denominadas como outras, em $23 \%$ os controles são feitos em papéis, $15 \%$ em planilhas, $42 \%$ fazem seus controles softwares específicos e em $19 \%$ os controles são efetuados em duas ou mais ferramentas.

O estudo mostra ainda que em $93 \%$ das empresas analisadas se faz algum tipo de controle/anotação, seja ele através de papel, planilha, software ou todos eles juntos. Esse dado mostra que nas empresas, independente do seu tamanho ou porte, há a preocupação em se fazer controles e anotações. Entretanto, é observado que $55 \%$ dos gestores ainda possuem restrições em relação à implantação de softwares nas empresas.

\subsection{Análise de Cluster}

Neste estudo procurou-se separar dois grupos de empresas (clusters), um com empresas com maior conhecimento e aplicação da gestão financeira e outro com empresas com menor conhecimento e aplicação da gestão financeira. Os dados da Tabela 9 apresentam as variáveis utilizadas na formação dos dois grupos. As variáveis foram submetidas a ANOVA (analysis of variance) e com exceção da variável "Controle de valores realizados", todas as demais presentes na tabela são significantes ao nível de $5 \%$ (teste F).

A finalidade do teste ANOVA não é verificar se os clusters são ou não diferentes, mas identificar qual ou quais das variáveis permitem a separação dos clusters.

Os dados apresentam 77 empresas agrupadas no cluster 1 e 123 empresas no cluster 2. Pode-se verificar que o grau de conhecimento e utilização da gestão financeira no grupo 1 é menor que os apresentados no grupo 2. Dessa forma, fica o cluster 2 caracterizado como grupo com maiores conhecimento e aplicação da gestão 
Práticas de gestão financeira e sua relação com o desempenho empresarial: um estudo com 200 empresas do centro oeste mineiro André Luis Ribeiro Lima, Hudson Carlos Silva Vidal, Leonardo Lemos da Silveira Santos, Ricardo César

financeira. Este mesmo grupo apresenta também, médias maiores nas duas variáveis de desempenho.

Os resultados médios e o desvio-padrão das respostas foram apresentados para cada cluster conforme Tabela 9. As 77 empresas agrupadas no cluster 1 apresentaram desempenho nos últimos três anos de 6,59 (em uma escala de 0 a 10). A média do desempenho, quando comparado às suas concorrentes foi de 6,38 (em uma escala de 0 a 10). O cluster 1 apresentou médias menores de desempenho quando comparado ao cluster 2 composto por 123 empresas e com desempenho médio de 7,31 e 7,78 (também com escala de 0 a 10).

Questionados sobre a projeção de valores orçados, aplicando-se o valor 1 para respostas positivas e 0 para respostas negativas, o grupo de empresas do cluster um apresentou média de 0,10 e o cluster 2 média de 0,41. Esse resultado indica maior uso de orçamentos por parte de empresas com melhor desempenho.

Os gestores foram questionados sobre o conhecimento e aplicação desse conhecimento no que diz respeito a "gestão de estoques", "gestão de custos", "gestão do caixa" e gestão do crédito". A escala para cada pergunta foi de 0 a 8 , sendo 0 nenhum conhecimento e nenhuma aplicação e 8 pleno conhecimento e plena aplicação. Em todas essas questões, as maiores médias são das empresas do cluster 2, ou seja, empresas com melhor desempenho também são aquelas que seus gestores afirmam ter maior conhecimento e aplicar mais determinadas ferramentas da administração financeira. 
Práticas de gestão financeira e sua relação com o desempenho empresarial: um estudo com 200 empresas do centro oeste mineiro André Luis Ribeiro Lima, Hudson Carlos Silva Vidal, Leonardo Lemos da Silveira Santos, Ricardo César

Tabela 9: Análise de cluster

\begin{tabular}{|c|c|c|c|c|}
\hline Variáveis & \multicolumn{2}{|c|}{ Cluster 1 (N=77) } & \multicolumn{2}{c|}{$\begin{array}{c}\text { Cluster 2 } \\
\text { (N=123) }\end{array}$} \\
\cline { 2 - 5 } & Média & $\begin{array}{c}\text { Desvio } \\
\text { Padrão }\end{array}$ & $\begin{array}{c}\text { Média } \\
\begin{array}{c}\text { Desvio } \\
\text { Padrão }\end{array}\end{array}$ \\
\hline Desempenho nos últimos três anos (escala de 0 a 10) & 6,59 & 2,20 & 7,31 & 1,52 \\
\hline $\begin{array}{c}\text { Desempenho comparado a concorrentes (escala de 0 a } \\
\text { 10) }\end{array}$ & 6,38 & 1,99 & 7,78 & 1,46 \\
\hline $\begin{array}{c}\text { Projeção de valores orçados (1 = realiza 0 = não } \\
\text { realiza) }\end{array}$ & 0,10 & 0,30 & 0,41 & 0,49 \\
\hline $\begin{array}{c}\text { Controle de valores realizados (1 = realiza 0 = não } \\
\text { realiza) }\end{array}$ & 0,84 & 0,37 & 0,80 & 0,40 \\
\hline $\begin{array}{c}\text { Conhecimento e aplicação da gestão de estoques } \\
\text { (escala de 0 a 8) }\end{array}$ & 3,09 & 2,07 & 7,17 & 1,57 \\
\hline $\begin{array}{c}\text { Conhecimento e aplicação da gestão de custos (escala } \\
\text { de 0 a 8) }\end{array}$ & 2,99 & 2,25 & 7,26 & 1,37 \\
\hline $\begin{array}{c}\text { Conhecimento e aplicação da gestão do caixa (escala } \\
\text { de 0 a 8) }\end{array}$ & 5,29 & 2,36 & 7,62 & 1,23 \\
\hline $\begin{array}{c}\text { Conhecimento e aplicação da gestão do crédito (escala } \\
\text { de 0 a 8) }\end{array}$ & 2,94 & 2,85 & 6,98 & 1,78 \\
\hline
\end{tabular}

Fonte: dados da pesquisa.

\subsection{Resultados e Discussão}

Quanto às práticas utilizadas pelos gestores das MPE's, observou-se no indicador financeiro lucro, que independente do porte das empresas, grande parte destes gestores apuram ou sabem quanto é o lucro obtido na empresa, se preocupam em saber o comportamento do patrimônio de suas empresas, se esse está aumentando ou diminuindo, especialmente nas empresas classificadas como "outras". Quanto ao indicador financeiro caixa, observou-se que a maioria dos gestores também se preocupa em apurar e saber quanto é o montante do caixa em suas empresas em determinado período.

O indicador rentabilidade mostrou que em $46 \%$ das empresas pesquisadas os gestores não se preocupam em saber qual é a sua rentabilidade, nem qual é o retorno dos proprietários ou dos sócios em relação ao capital investido; eles estão interessados apenas no pró-labore, ou seja, no rendimento do seu trabalho na empresa.

Quanto aos controles efetuados nas empresas, apenas em 6,1\% não se faz qualquer tipo de controle/anotação, no restante das empresas há controles através de 
Práticas de gestão financeira e sua relação com o desempenho empresarial: um estudo com 200 empresas do centro oeste mineiro

André Luis Ribeiro Lima, Hudson Carlos Silva Vidal, Leonardo Lemos da Silveira Santos, Ricardo César

papéis, planilhas e softwares. Outro dado interessante foi observado na representatividade de empresas que fazem seus controles em papéis $(31,5 \%)$, quase $1 / 3$ do total. Também cabe ressaltar que ainda falta um planejamento formal nas MPE's ao se realizar os controles/anotações, visto que nessas empresas os controles são efetuados com base no realizado, ou seja, no que já ocorreu dentro da empresa; não procuram estimar e planejar as receitas, custos e despesas.

Quanto ao desempenho, avaliando o comportamento nos últimos três anos de atuação, encontrou-se uma média de 7,5 (em uma escala de 0 a 10). Esse desempenho é em relação aos seus concorrentes. Com base nessas informações, a Tabela 2 mostra um comparativo entre dois grupos de empresas, sendo o primeiro formado por aquelas empresas que tiveram seu desempenho acima da média e o segundo grupo formado por aquelas empresas cujo desempenho foi abaixo da média.

Percebeu-se no primeiro grupo que os gestores apresentam ter maior conhecimento sobre as ferramentas financeiras analisadas e demonstraram usufruir mais dessas ferramentas devido ao grau de conhecimento que eles possuem. Foi observado no segundo grupo a inferioridade do grau de conhecimento dos gestores em relação ao primeiro grupo, mostrando que os gestores das empresas que ficaram abaixo da média afirmaram conhecer e utilizar menos as ferramentas financeiras.

As análises de cluster apontam que as empresas podem ser separadas por seu nível de conhecimento e aplicação da gestão financeira. Além disso, o grupo com maior conhecimento e aplicação da gestão financeira apresenta as melhores médias de desempenho.

\section{CONCLUSÃO}

O objetivo proposto na pesquisa foi identificar e avaliar as práticas ligadas à administração financeira e à contabilidade, utilizadas pelos gestores de empresas do Centro Oeste de Minas Gerais, associando-as ao seu desempenho. 
Práticas de gestão financeira e sua relação com o desempenho empresarial: um estudo com 200 empresas do centro oeste mineiro

André Luis Ribeiro Lima, Hudson Carlos Silva Vidal, Leonardo Lemos da Silveira Santos, Ricardo César

Com base nos dados apresentados na pesquisa, concluiu-se que grande parte das empresas analisadas se classifica como microempresas que atuam no setor de comércio e se enquadram no sistema de tributação Simples Nacional. Quanto à apuração de alguns indicadores financeiros como lucro, caixa e rentabilidade foi observado que os gestores se preocupam em saber se o patrimônio está aumentando ou diminuindo e se haverá sobra ou falta de caixa em determinado período, porém, quanto à rentabilidade, a maior parte dos entrevistados afirma não mensurar a avaliar este indicador.

Quanto aos controles realizados nas empresas, observou-se que em apenas 6,1\% não se faz qualquer tipo de controle/anotação, porém em quase 1/3 das empresas pesquisadas ainda se utiliza controles em papéis, deixando de utilizar softwares específicos ou planilhas.

As análises de cluster apontam que as empresas podem ser separadas por seu nível de conhecimento e aplicação da gestão financeira. Além disso, o grupo com empresas que apresentam maior conhecimento e aplicação da gestão financeira foi o grupo que apresentou as melhores médias de desempenho.

Com este estudo não se pode afirmar que o conhecimento e adoção de instrumentos de controle $\mathrm{e}$ análise financeira influenciam 0 desempenho das organizações, porém permite abrir a discussão sobre a maior presença desses instrumentos financeiros em empresas com melhor desempenho.

\section{REFERÊNCIAS}

ASSAF NETO, Alexandre; SILVA, César Augusto Tibúrcio. (2007). Administração do capital de giro. (5 ed.). São Paulo: Atlas.

CABELLO, Otavio Gomes; GALLO, Mauro Fernando; PEREIRA, Carlos Alberto. (2007). O SIMPLES Nacional, realmente, reduz a carga tributária das empresas? Um estudo de caso. XIV Congresso Brasileiro de Custos, Anais..., João Pessoa, PB, dez.

CHENG, A.; MENDES, M.M.; A Importância e a Responsabilidade da Gestão Financeira na Empresa. Caderno de Estudos no 01, São Paulo, FIPECAFI - Outubro/1989. 
Práticas de gestão financeira e sua relação com o desempenho empresarial: um estudo com 200 empresas do centro oeste mineiro André Luis Ribeiro Lima, Hudson Carlos Silva Vidal, Leonardo Lemos da Silveira Santos, Ricardo César

FÁVERO, L. P. et al. (2009). Análise de dados: modelagem multivariada para tomada de decisões. Rio de Janeiro: Elsevier.

GITMAN, L. J. (2010). Princípios de administração financeira. (12 ed.). São Paulo: Pearson.

IBGE, Cadastro Central de Empresas 2007; Rio de Janeiro: IBGE, 2007.

IUDÍCIBUS, Sérgio de. (coordenador). (2010). Contabilidade introdutória. (11 ed.). São Paulo: Atlas.

LEONE, George Sebastião Guerra; LEONE, Rodrigo José Guerra. (2004). Dicionário de custos. São Paulo: Atlas.

LEONE, Nilda. (1991). A dimensão física das pequenas e médias empresas: a procura de um critério homogeneizador. Revista de Administração de Empresas, São Paulo, v.31, n.2, abr./jun.

MALHOTRA, Naresh K. et al. (2006). Introdução à pesquisa de marketing. São Paulo: Prentice Hall.

MARTINS, Eliseu. (2010). Contabilidade de custos. (10 ed.). São Paulo: Atlas.

MATIAS, G. A.; LOPES JR., F. (2002). Administração financeira nas empresas de pequeno porte. São Paulo: Manole.

MIGLIATO, A. L. T. (2004). Planejamento estratégico situacional aplicado à pequena empresa: estudo comparativo de casos em empresas do setor de serviço (hoteleiro) da região de Brotas - SP. São Carlos. (Dissertação de Mestrado). Universidade de São Paulo - Escola de Engenharia de São Carlos.

MONTEIRO, A. A. S. M. (2003). Fluxos de caixa e capital de giro: uma adaptação do modelo de Fleuriet. In: SEMINÁRIO DE CONTABILIDADE E CONTROLADORIA, 2. São Paulo. Anais... São Paulo: FEA-USP, 2002. Disponível em: http://www.eac.fea.usp.br Acesso em: 4/mai/2009.

OTTOBONI, Célia e PAMPLONA, Edson de O. (2001, outubro). Proposta de Pesquisa para Avaliar a Necessidade de se Medir o Desempenho Financeiro das Micro e Pequenas Empresas. XXI Encontro Nacional de Engenharia de Produção, Salvador, BA, Anais... 
Práticas de gestão financeira e sua relação com o desempenho empresarial: um estudo com 200

empresas do centro oeste mineiro

André Luis Ribeiro Lima, Hudson Carlos Silva Vidal, Leonardo Lemos da Silveira Santos, Ricardo César

Alves

PERIN, MARCELO G; SAMPAIO, CLÁUDIO H. (1999). Performance empresarial: uma comparação entre indicadores subjetivos e objetivos. In: Encontro Nacional de Pósgraduação em Administração, Foz do Iguaçu - PR. Anais... Foz do Iguaçu: ENANPAD.

SANTOS, E. O. (2010). Administração financeira da pequena e média empresa. (2 ed.). São Paulo: Atlas.

SANTOS, Leonardo Lemos da Silveira; ALVES, Ricardo César; ALMEIDA, Kenneth Nunes Tavares. (2007, outubro). Formação de estratégia nas micro e pequenas empresas: um estudo no centro-oeste mineiro. In: Revista de Administração de Empresas, São Paulo, v.47, n. 4, p. 59-73.

SEBRAE - Serviço Brasileiro de Apoio às Micros e Pequenas Empresas. Disponível em: <http://www.sebrae.com.br>. Acesso em: 13/mar/2009

SILVA, J.F.; CARNEIRO, J.M.T.; ROCHA, A.M.C.; HEMAIS, C.A. (2005). Mensuração do Desempenho Organizacional: Questões Conceituais e Metodológicas. II Encontro de Estudos em Estratégia. Rio de Janeiro. 2005. Anais... Rio de Janeiro. Nacional.

Data de Submissão: 16/01/2014

Data de Aceite: 23/06/2014 